[3] J. Effront. Les catalyseurs biochimiques dans la vie et dans l'industrie, p. 96.

[4] - - , p. 97 .

[5] - - , p. 93.

[6] P. Partsi. Ricerche sulla "Cynarasi", Annali Istituto Spallanzani, vol. I, 1930, p. 147.

[7] C. Christen et E. Virasoro, Loc. cit.

[8] Haldane. Enzyme, p. 70.

$[9]-,-, p, 71$.

\title{
LA STABILISATION DU LAIT PAR LA DÉSACIDIFICATION ÉLECTRIQUE
}

\author{
par le Proíesseur Dr W. WINKLER (Vienne).
}

Le Lait a décrit, dans son numéro 132, de février 1934, un nouveau procédé qui permet d'une façon très simple, de réduire le degré d'acidité du lait par le courant électrique. Ce procédé permet de restituer à un lait, titrant $25^{\circ}$ Dornic d'acidité, la faculté, qu'il avait perdue, de pouvoir être bouilli et pasteurisé. Ceci présente un intérêt primordial également pour l'utilisation de la crème hyperacide dans la fabrication du beurre.

Ce procédé a trouvé son application industrielle dans les appareils de désacidification électrique construits par la Société "Elact" à Vienne.

L'article précité signalait đéjà que le traitement indiqué réduit la teneur du lait en bactéries et en germes. Les colibacilles nocifs se trouvant beaucoup plus atteints que les bactéries de l'acide lactique, on constate done une amélioration de la flore bactérienne du lait. La réduction de la teneur en germes implique, cela va de soi, un accroissement de la stabilité du lait, une prolongation de la durée de sa faculté d'ébullition.

Si le lait désacidifié est maintenu à basse température, entre 7 et $8^{\circ} \mathrm{C}$, , on augmente de 12 à 24 heures au moins - suivant le degré d'acidité originel - le temps pendant lequel le lait conserve sa faculté d'ébullition et de pasteurisation. A des températures plus élevées, à $20^{\circ}$ par exemple, l'augmentation de la stabilité est moindre, mais elle atteint toujours quelques heures au moins. Il faut, toutefois, que le lait traité ne titre pas plus de $38^{\circ}$ Dornic et que la désacidifieation soit poussée suffisamment loin.

Après le traitement, l'acidité reprend, d'abord, très lentement; elle monte, au contraire, très rapidement par la suite, ce qui s'explique par le fait que le procédé provoque la prépondérance, dans la flore, des bactéries de l'acide lactique.

L'accroissement de la stabilité est beaucoup plus important quand, après la désacidification, le lait est pasteurisé. On constate 


\section{Lait désacidifié non pasteurisé:}

a) De 72 à 96 heures, soit en moyenne 84 heures, gardé vers $10^{\circ} \mathrm{C}$;

b) De 24 à 30 heures, soit en moyenne 27 heures, gardé entre $19^{\circ}$ et $27^{\circ} \mathrm{C}$.

\section{Lait désacidifié el pasteurisé :}

a) 120 heures, soit 5 jours, gardé vers $10^{\circ} \mathrm{C}$. ;

b) 40 heures, soit 1 jour et demi, gardé entre 19 et $27^{\circ} \mathrm{C}$.

On voit done que la désacidification électrique a augmenté la stabilité de 60 heures, en moyenne, à basse température et de 15 heures à température élevée pour le lait non pasteurisé ; en pasteurisant, après avoir désacidifié, les accroissements de stabilité correspondants ont été respectivement de 96 heures et de 28 heures.

Les courbes ci-jointes montrent très clairement la montée progressive et la valeur absolue de l'acidité du lait, soumis à l'essai.

Cet essai a montré, d'autre part, que, pasteurisé ou non, le lait traité en l'occurrence accusait une limite de fluidité inférieure à ce qu'elle est d'habitude, ainsi que, peut-être, certains signes d'épaississement, qui se produisent bien rarement dans d'autres circonstances, mais qui n'en ont pas moins, dans le cas présent, pesé d'une façon défavorable sur la stabilité.

Les expériences faites jusqu'à ce jour montraient que la désacidification électrique du lait abaissait la limite d'ébullition du lait de 2 à $3^{\circ} 5$ Dornic.

Dans le eas présent, la limite d'ébullition du lait non traité avait été, comme nous l'avons vu, déjà fortement réduite (2205 Dornic, au lieu de 26), par suite du long séjour dans les bidons.

C'est ce qui explique que, le lait traité en l'occurrence, accusa, même après pasteurisation, une limite d'ébullition inférieure à la normale.

On n'a pu constater aucune action défavorable du traitement sur l'odeur ni sur la saveur du lait, qui se sont trouvées absolument normales après pasteurisation.

Les prévisions théoriques ont done trouvé leur pleine confirmation au cours de ces essais.

La faculté d'ébullition, la stabilité du lait sont augmentées d'une façon notable par la désacidification électrique, même quand le lait est conservé à température assez élevée, mais particulièrement quand il a été pasteurisé. 